\title{
COMPARAÇÃO DE TÉCNICAS DE DETERMINAÇÃO DE ÉSTERES EM CACHAÇA
}

\author{
Eduardo S. P. Nascimento, Daniel R. Cardoso e Douglas W. Franco* \\ Departamento de Química e Física Molecular, Instituto de Química de São Carlos, Universidade de São Paulo, CP 780, 13560-970 \\ São Carlos - SP, Brasil
}

Recebido em 28/10/08; aceito em 25/5/09; publicado na web em 13/11/09

\begin{abstract}
COMPARISON OF ESTERS DETERMINATION TECHNIQUES IN CACHAÇA. An analytical comparison of three different techniques for quantitative profile of esters in cachaça is reported. The Ministério da Agricultura Pecuária e Abastecimento (MAPA) recommends the use of GC/FID or volumetry. Despite being laborious and lacking in chemical speciation, the volumetric technique for total ester content shows to be appropriate, reproducible, and accurate for the analysis of cachaça. However, the GC/FID suggested by MAPA, considering only ethyl acetate, shows inaccuracy, underestimating the total ester content by a median factor of $72 \%$, mainly due to the absence of ethyl lactate analysis. On the other hand, the GC/MS technique that comprises the analysis and speciation of nine esters, including ethyl lactate, proved to be reproducible, simple, fast and accurate for the analysis of total ester content in cachaça. Thus, the total ester content results obtained using GC/FID must be considered with precaution.
\end{abstract}

Keywords: esters; cachaça; GC/MS.

\section{INTRODUÇÃO}

Apesar dos esforços do governo em promover a exportação da cachaça, o volume de exportações é ainda irrisório quando comparado ao total produzido (em torno de um bilhão e quinhentos milhões de litros por ano). Em 2002, foram exportados 14,8 milhões de litros, o que representou pouco menos de $1 \%$ da produção total, gerando US\$ 8,5 milhões em divisas. ${ }^{1-3}$

Assim como as outras bebidas destiladas, a cachaça é caracterizada organolepticamente pela presença de congêneres, que representam menos de $1 \%$ em massa. Estes compostos secundários, tais como álcoois superiores, ésteres, ácidos carboxílicos e compostos carbonílicos, são importantes para o aroma e sabor (flavor) dos destilados. ${ }^{4-7}$

Os ésteres, presentes nas bebidas destiladas, são provenientes de duas fontes distintas: os ésteres alifáticos, tais como acetato de etila e butanoato de etila, originam-se durante a fermentação alcoólica através do metabolismo secundário intracelular das leveduras; ${ }^{8}$ os ésteres gerados através da interconversão dos compostos fenólicos, tais como siringato de etila e o vanilato de etila, e os ésteres extraídos da madeira (homovanilato de metila e siringato de metila), são consequência do processo de envelhecimento..$^{9,10}$

Em trabalho anterior ${ }^{11}$ foi relatada pela primeira vez a presença do éster lactato de etila em aguardente, ressaltando-se o fato de este ser o segundo éster mais abundante na cachaça. A presença de lactato de etila na cachaça está relacionada com a contaminação do mosto por bactérias (Lactobacillus spp.) responsáveis pela fermentação láctica, favorecida pelo controle deficiente da fermentação alcoólica. A origem destas bactérias no mosto está associada à própria matériaprima (cana-de-açúcar, levedura e água) e ao local de produção da bebida (planta). ${ }^{12}$ Assim, a presença de lactato de etila constitui de per si um indicador da qualidade de fermentação.

De acordo com a legislação brasileira, o valor máximo permitido para soma do teor total de ésteres expressos em acetato de etila é 200 mg $100 \mathrm{~mL}^{-1}$ de álcool anidro. ${ }^{13} \mathrm{O}$ Ministério da Agricultura, Pecuária e Abastecimento - MAPA sugere a determinação do teor total de ésteres expressos em acetato de etila por duas técnicas. ${ }^{14} \mathrm{~A}$ primeira é baseada na técnica volumétrica, que envolve a titulação dos ésteres totais após

*e-mail: douglas@iqsc.usp.br sua hidrólise em meio alcalino; a segunda, via cromatografia gasosa utilizando detector de ionização em chama (CG/DIC) onde apenas o acetato de etila é monitorado. Quando se aplica a primeira técnica, os ésteres totais são analisados; entretanto, o mesmo não ocorre quando o segundo procedimento é utilizado. O lactato de etila representa mais de um quarto do total de ésteres presentes nas aguardentes, portanto, sua contribuição à fração de ésteres totais não deve ser negligenciada. ${ }^{11}$

Neste trabalho as duas técnicas sugeridas pelo MAPA, a volumétrica e a cromatográfica CG/DIC, são comparadas com a técnica utilizando a técnica de cromatografia gasosa com detector de espectrometria de massas operando no modo seletivo de íons (CG/EM-MSI), que se baseia na determinação de nove ésteres, incluindo o lactato de etila.

\section{PARTE EXPERIMENTAL}

\section{Amostras}

Foram analisadas no total 23 amostras de cachaças. Destas, 11 amostras foram coletadas de diferentes produtores e em diferentes cidades localizadas no interior do estado de São Paulo. Estas amostras foram coletadas imediatamente após a sua destilação, no próprio local de produção, devidamente lacradas para que a perda dos voláteis fosse mínima e armazenadas em geladeira $\left(5 \pm 2{ }^{\circ} \mathrm{C}\right)$. As demais são amostras de cachaça envelhecidas comerciais fornecidas e certificadas pelos produtores: Campanari, São Saruê, Porão, Caribeña Ouro, Tiquara, Aroma Brasil Jequitiba, Aroma Brasil Castanheira, Reserva do Tanoeiro, Armazém Vieira Terra, Armazém Vieira Safira, Souza Andrade/Fonseca, e Valle.

\section{Reagentes}

Todos os reagentes utilizados foram de grau de pureza analítica (> $99 \%$ ). Os padrões de acetato de etila, butanoato de etila, hexanoato de etila, lactato de etila, octanoato de etila, nonanoato de etila, decanoato de etila, octanoato de isoamila e dodecanoato de etila e o padrão interno 4-metil 2-pentanol foram obtidos da Sigma-Aldrich e utilizados sem tratamento prévio. As soluções padrões de ésteres foram preparadas em solução alcoólica (etanol/água) $40 \%$ v/v. Para o preparo da solução alcoólica foi utilizado álcool etílico grau HPLC (Fisher Scientific). A água ultra-pura, $18,2 \mathrm{M} \Omega \mathrm{cm}^{-2}$ a $25^{\circ} \mathrm{C}$, foi obtida através de um sistema 
Milli-Q (Millipore). A solução de hidróxido de sódio 0,10 N (Spectrum) foi padronizada com ácido oxálico (Merck) como padrão primário. A solução de ácido sulfúrico 0,10 N (Merck) foi padronizada utilizando-se da solução de hidróxido de sódio, conforme recomendação do MAPA.

\section{Volumetria}

As análises volumétricas das amostras foram realizadas de acordo com o método proposto pelo MAPA. ${ }^{14}$ Transferiu-se $100 \mathrm{~mL}$ da amostra para um Erlenmeyer de $250 \mathrm{~mL}$ e neutralizou-se com solução de hidróxido de sódio, usando como indicador fenolftaleína. Adicionou-se $10 \mathrm{~mL}$ da solução de hidróxido de sódio $0,10 \mathrm{~N}$ e deixou-se em refluxo durante $2 \mathrm{~h}$ em um banho a $60 \pm 0,2{ }^{\circ} \mathrm{C}$. Resfriou-se rapidamente utilizando um banho de gelo e adicionou-se $10 \mathrm{~mL}$ da solução de ácido sulfúrico $0,10 \mathrm{~N}$. Titulou-se o excesso de ácido sulfúrico com a solução de hidróxido de sódio padronizada até coloração rósea.

Para as análises volumétricas das amostras envelhecidas foi utilizado um pHmetro PHM 250 Radiometer Analytical (Radiometer) e um eletrodo de vidro combinado para a determinação do ponto de equivalência.

\section{Cromatografia gasosa acoplada ao detector de ionização em chama (CG/DIC) ${ }^{4}$}

As análises foram realizadas utilizando um sistema cromatográfico Hewlett-Packard 5890-A equipado com um injetor split-splitless e um detector de ionização em chama. A coluna cromatográfica empregada foi uma HP-FFAP (50 $\mathrm{m}$ x $0,20 \mathrm{~mm} \times 0,33 \mu \mathrm{m}$ de espessura do filme da fase estacionária de polietileno glicol esterificado). A programação de temperatura para o forno foi a seguinte: temperatura inicial de $40{ }^{\circ} \mathrm{C}$ por 2 min e elevada a $10{ }^{\circ} \mathrm{C} \min ^{-1}$ até $200{ }^{\circ} \mathrm{C}$. As temperaturas do injetor e do detector foram de $220^{\circ} \mathrm{C}$.

A injeção direta das amostras foi realizada no modo split com razão 1:20, injetando-se $1 \mu \mathrm{L}$ de amostra. A pressão do gás de arraste (hidrogênio, (4.5) Analítico, White-Martins) na cabeça da coluna foi de $62 \mathrm{kPa}$. Os fluxos dos gases para alimentação do detector foram: $30 \mathrm{~mL} \mathrm{~min}^{-1}$ para o hidrogênio e $300 \mathrm{~mL} \mathrm{~min}^{-1}$ para o ar sintético. A quantificação dos ésteres nas amostras foi realizada através do método da adição de padrão utilizando $n$-hexanol (100 $\left.\mathrm{mg} \mathrm{L}^{-1}\right)$ como padrão interno.

\section{Cromatografia gasosa acoplada ao detector de espectrometria de massas (CG/EM-MSI) ${ }^{11}$}

As análises foram realizadas em um cromatógrafo (Shimadzu GC-17A), equipado com um detector de espectrometria de massas (Shimadzu QP5050A) operando no modo de impacto eletrônico (70 eV), monitoramento seletivo de íons (MSI) e injeção direta da amostra no modo split.

A coluna cromatográfica empregada foi uma HP-FFAP $(50 \mathrm{~m}$ x 0,20 mm x 0,33 $\mu \mathrm{m}$ de espessura do filme da fase estacionária de polietileno glicol esterificado) e a programação de temperatura para o forno foi a seguinte: temperatura inicial de $35{ }^{\circ} \mathrm{C}$ elevada a $5{ }^{\circ} \mathrm{C}$ $\min ^{-1}$ até $180^{\circ} \mathrm{C}$, e então, elevada a $20^{\circ} \mathrm{C}$ min $^{-1}$ até $220^{\circ} \mathrm{C}$ e mantida por $5 \mathrm{~min}$. As temperaturas do bloco de injeção e da interface do detector foram de $220{ }^{\circ} \mathrm{C}$.

O volume de injeção foi de $1 \mu \mathrm{L}$ com um split de 1:15 utilizando hélio como gás de arraste com vazão de $1,0 \mathrm{~mL} \mathrm{~min}^{-1}$. Os dados foram coletados em triplicatas e para a análise quantitativa empregou-se o método da adição de padrão. O padrão interno foi o 4-metil-2pentanol $\left(50,1 \mathrm{mg} \mathrm{L}^{-1}\right)$.

Os íons utilizados nas análises no modo MSI (monitoramento seletivo de íon) (Tabela 1) foram escolhidos de acordo com o espectro de massas previamente obtido para cada padrão analítico no modo de varredura de espectro (Scan). Fatores como intensidade do pico e interferência foram as principais características consideradas na escolha dos íons. Os parâmetros de validação do método encontramse descritos na literatura.

Tabela 1. Programação das janelas de aquisição para os íons monitorados $(\mathrm{m} / \mathrm{z})$ na análise de ésteres por CG/EM-MSI

\begin{tabular}{lccc}
\hline Janela & $\begin{array}{c}\text { Tempo de aquisição } \\
(\mathrm{min})\end{array}$ & $\begin{array}{c}\text { Íon } \\
(\mathrm{m} / \mathrm{z})\end{array}$ & Analito \\
\hline 1 & $4,00-6,50$ & 70 & Acetato de etila \\
2 & $6,50-8,00$ & 88 & $\begin{array}{c}\text { Butanoato de etila } \\
3\end{array}$ \\
$4,00-11,40$ & 69 & 4-metil 2-pentanol \\
4 & $11,40-15,00$ & 88 & Hexanoato de etila \\
5 & $15,00-16,25$ & 75 & Lactato de etila \\
6 & $16,25-22,70$ & 88 & $\begin{array}{c}\text { Octanoato de etila } \\
\text { Nonanoato de etila }\end{array}$ \\
7 & $22,70-25,00$ & 70 & Octanoato de isoamila \\
8 & $25,00-29,00$ & 88 & Dodecanoato de etila \\
\hline
\end{tabular}

\section{Análise estatística}

Os testes de normalidade e ANOVA foram realizados através do software Minitab Release 14 (Statiscal Software, State College, Pennsylvania, US).

\section{Grau alcoólico das amostras}

A determinação do grau alcoólico real das amostras foi realizada através de determinações de densidade utilizando uma balança analítica Shimadzu modelo AW120 e um picnômetro de 25,0 mL. ${ }^{14}$

\section{RESULTADOS E DISCUSSÃO}

A Figura 1 apresenta um cromatograma dos padrões de ésteres e um cromatograma característico de uma amostra de cachaça não comercial obtido por CG/EM-MSI. A Tabela 2 apresenta as concentrações de ésteres obtidas para as amostras de cachaça não comercias analisadas por CG/EM-MSI. Os valores da graduação alcoólica para as 11 amostras de cachaça, utilizados para o cálculo da concentração em mg de ésteres por $100 \mathrm{~mL}$ de álcool anidro, encontram-se listados na Tabela 3. Como pode ser observado, o acetato de etila é o éster presente em maior concentração representando em média $71,8 \%$ do teor total de ésteres, enquanto o lactato de etila é o segundo mais abundante, representando $26,8 \%$ em média.

Um cromatograma típico de uma amostra de cachaça não comercial, analisada por injeção direta, obtido por CG/DIC é apresentado na Figura 2. Esta técnica permite quantificar, além do acetato de etila, alguns álcoois (entre eles metanol, álcool iso-amílico, iso-butanol, $n$-butanol e $n$-propanol) e o ácido acético. ${ }^{4} \mathrm{~A}$ Tabela 3 lista a concentração de acetato de etila obtida por CG/DIC para as 11 amostras de cachaça não comerciais analisadas.

A Tabela 3 lista, também, a soma do teor total de ésteres obtida pelas duas técnicas sugeridas pelo MAPA, volumetria e CG/DIC, e por CG/EM-MSI. De acordo com a legislação brasileira, o valor máximo permitido para a soma do teor total de ésteres expressos em acetato de etila é de $200 \mathrm{mg}$ por $100 \mathrm{~mL}$ de álcool anidro. Dentre todas as amostras analisadas nenhuma ultrapassou o limite estabelecido pela legislação. ${ }^{13}$ 
Tabela 2. Concentrações dos ésteres (mg $100 \mathrm{~mL}^{-1}$ álcool anidro) obtidas para as amostras de cachaça não comerciais analisadas por CG/EM-MSI

\begin{tabular}{|c|c|c|c|c|c|}
\hline Amostra & Acetato de etila & Butanoato de etila & Hexanoato de etila & Lactato de etila & Octanoato de etila \\
\hline Am01 & $70,1( \pm 0,79)$ & $0,189( \pm 0,01)$ & $0,733( \pm 0,10)$ & $25,3( \pm 0,19)$ & $0,676( \pm 0,10)$ \\
\hline $\mathrm{Am02}$ & $88,2( \pm 0,43)$ & $<\mathrm{LD}$ & $0,163( \pm 0,01)$ & $17,0( \pm 0,03)$ & $0,042( \pm 0,001)$ \\
\hline $\mathrm{Am03}$ & $57,7( \pm 0,21)$ & $0,585( \pm 0,001)$ & $1,07( \pm 0,001)$ & $33,9( \pm 0,12)$ & $0,959( \pm 0,01)$ \\
\hline Am04 & $51,9( \pm 0,16)$ & $<\mathrm{LD}$ & $0,933( \pm 0,01)$ & $4,94( \pm 0,02)$ & $0,245( \pm 0,01)$ \\
\hline $\mathrm{Am05}$ & $126,9( \pm 0,32)$ & $<\mathrm{LD}$ & $0,399( \pm 0,002)$ & $8,54( \pm 0,002)$ & $<\mathrm{LD}$ \\
\hline Am06 & $89,9( \pm 0,12)$ & $<\mathrm{LD}$ & $1,38( \pm 0,01)$ & $77,5( \pm 0,02)$ & $0,114( \pm 0,01)$ \\
\hline $\mathrm{Am07}$ & $54,6( \pm 0,21)$ & $<\mathrm{LD}$ & $<\mathrm{LD}$ & $11,8( \pm 0,05)$ & $<\mathrm{LD}$ \\
\hline Am08 & $30,7( \pm 0,11)$ & $<\mathrm{LD}$ & $<\mathrm{LD}$ & $20,8( \pm 0,02)$ & $0,075( \pm 0,002)$ \\
\hline Am09 & $57,3( \pm 0,04)$ & $<\mathrm{LD}$ & $0,101( \pm 0,004)$ & $82,6( \pm 0,03)$ & $0,806( \pm 0,03)$ \\
\hline Am10 & $97,3( \pm 0,13)$ & $<\mathrm{LD}$ & $<\mathrm{LD}$ & $10,7( \pm 0,06)$ & $0,204( \pm 0,01)$ \\
\hline Am11 & $114( \pm 0,01)$ & $<\mathrm{LD}$ & $0,056( \pm 0,002)$ & $21,0( \pm 0,004)$ & $0,148( \pm 0,03)$ \\
\hline Amostra & Nonanoato de etila & Decanoato de etila & Octanoato de isoamila & Dodecanoato de etila & \\
\hline Am01 & $0,048( \pm 0,001)$ & $1,29( \pm 0,18)$ & $0,024( \pm 0,002)$ & $0,380( \pm 0,01)$ & \\
\hline $\mathrm{Am02}$ & $<\mathrm{LD}$ & $0,054( \pm 0,04)$ & $<\mathrm{LD}$ & $<\mathrm{LD}$ & \\
\hline $\mathrm{Am03}$ & $0,045( \pm 0,003)$ & $1,61( \pm 0,02)$ & $<\mathrm{LD}$ & $0,511( \pm 0,01)$ & \\
\hline $\mathrm{Am04}$ & $<\mathrm{LD}$ & $0,558( \pm 0,05)$ & $<\mathrm{LD}$ & $0,091( \pm 0,02)$ & \\
\hline $\mathrm{Am05}$ & $<\mathrm{LD}$ & $0,085( \pm 0,01)$ & $<\mathrm{LD}$ & $0,063( \pm 0,01)$ & \\
\hline Am06 & $<\mathrm{LD}$ & $0,086( \pm 0,01)$ & $<\mathrm{LD}$ & $<\mathrm{LD}$ & \\
\hline $\mathrm{Am07}$ & $<\mathrm{LD}$ & $0,334( \pm 0,04)$ & $<\mathrm{LD}$ & $0,182( \pm 0,02)$ & \\
\hline Am08 & $<\mathrm{LD}$ & $0,215( \pm 0,01)$ & $<\mathrm{LD}$ & $0,126( \pm 0,03)$ & \\
\hline Am09 & $<\mathrm{LD}$ & $1,20( \pm 0,05)$ & $<\mathrm{LD}$ & $0,298( \pm 0,03)$ & \\
\hline Am10 & $<\mathrm{LD}$ & $0,715( \pm 0,07)$ & $<\mathrm{LD}$ & $0,216( \pm 0,04)$ & \\
\hline Am11 & $0,150( \pm 0,04)$ & $<\mathrm{LD}$ & $<\mathrm{LD}$ & & \\
\hline
\end{tabular}

$<\mathrm{LD}=$ abaixo do limite de detecção.

Tabela 3. Teor total de ésteres das amostras de cachaça não comerciais obtido por volumetria, CG/EM-MSI e CG/DIC (mg $100 \mathrm{~mL}^{-1}$ álcool anidro)

\begin{tabular}{lcccc}
\hline Amostra Volumetria* & CG/EM-MSI & CG/DIC & $\begin{array}{c}\text { Teor } \\
\text { alcoólico } \\
\left({ }^{\circ} \text { GL }\right)^{\mathrm{a}}\end{array}$ \\
\hline Am01 & 105,0 & $98,7( \pm 0,84)$ & $72,4( \pm 0,10)$ & 55,4 \\
Am02 & 116,6 & $105,5( \pm 0,43)$ & $86,8( \pm 0,11)$ & 40,5 \\
Am03 & 87,7 & $96,4( \pm 0,24)$ & $53,7( \pm 0,09)$ & 58,6 \\
Am04 & 64,3 & $58,7( \pm 0,17)$ & $48,9( \pm 0,13)$ & 44,6 \\
Am05 & 143,9 & $136,0( \pm 0,32)$ & $120,7( \pm 0,12)$ & 45,6 \\
Am06 & 159,7 & $169,0( \pm 0,12)$ & $95,9( \pm 0,03)$ & 32,2 \\
Am07 & 66,3 & $66,9( \pm 0,22)$ & $53,6( \pm 0,07)$ & 33,0 \\
Am08 & 54,0 & $51,9( \pm 0,12)$ & $30,1( \pm 0,19)$ & 48,3 \\
Am09 & 145,6 & $142,3( \pm 0,08)$ & $59,0( \pm 0,01)$ & 46,3 \\
Am10 & 104,3 & $109,1( \pm 0,16)$ & $95,7( \pm 0,07)$ & 50,9 \\
Am11 & 142,1 & $135,3( \pm 0,05)$ & $111( \pm 0,10)$ & 38,5 \\
\hline
\end{tabular}

${ }^{a}=$ Teor alcoólico expresso em graus GL (graus Gay-Lussac \% v/v de álcool etílico). *Incerteza estimada em 2,2 mg $100 \mathrm{~mL}^{-1}$.
Com o intuito de se comparar os resultados da Tabela 3, ou seja, a soma do teor total de ésteres obtida pelas diferentes técnicas foi realizada uma análise de variância simples (one way ANOVA). ${ }^{15}$ Anteriormente foi realizado o teste de normalidade de ShapiroWilk a um nível de confiança de $0,05 .{ }^{15}$ Os dados experimentados demonstraram uma distribuição normal, obtendo-se para os dados de volumetria $\mathrm{p}=0,40861$, para CG/EM-MSI $\mathrm{p}=0,72530$ e para CG/ DIC $\mathrm{p}=0,72680$. As amostras de cachaça analisadas pela técnica volumétrica e CG/EM-MSI não apresentaram diferenças significativas nos valores encontrados segundo o teste ANOVA realizado em nível de confiança de 0,05 ( $p=0,91095)$. Por outro lado, os resultados obtidos pela análise por CG/DIC diferiram significativamente, a um nível de confiança de 0,05 , dos resultados obtidos pelas outras duas técnicas. Comparando-se os resultados obtidos por CG/DIC com os obtidos por CG/EM-MSI e os obtidos por volumetria $\mathrm{p}=0,04047 \mathrm{e}$ $p=0,03027$, respectivamente.

Estes resultados eram esperados, pois a técnica CG/DIC recomendada pelo MAPA não leva em consideração a presença do lactato de etila. De acordo com os dados obtidos por CG/EM-MSI (Tabela 2) o lactato de etila é o segundo éster mais abundante podendo, em alguns casos, representar até 58,0\% dos ésteres analisados. Dessa maneira, o teor total de ésteres determinado pela técnica de CG/DIC recomendado pelo MAPA, análise de acetato de etila, é em média $30 \%$ inferior aos teores obtidos por volumetria e por CG/EM-MSI. 


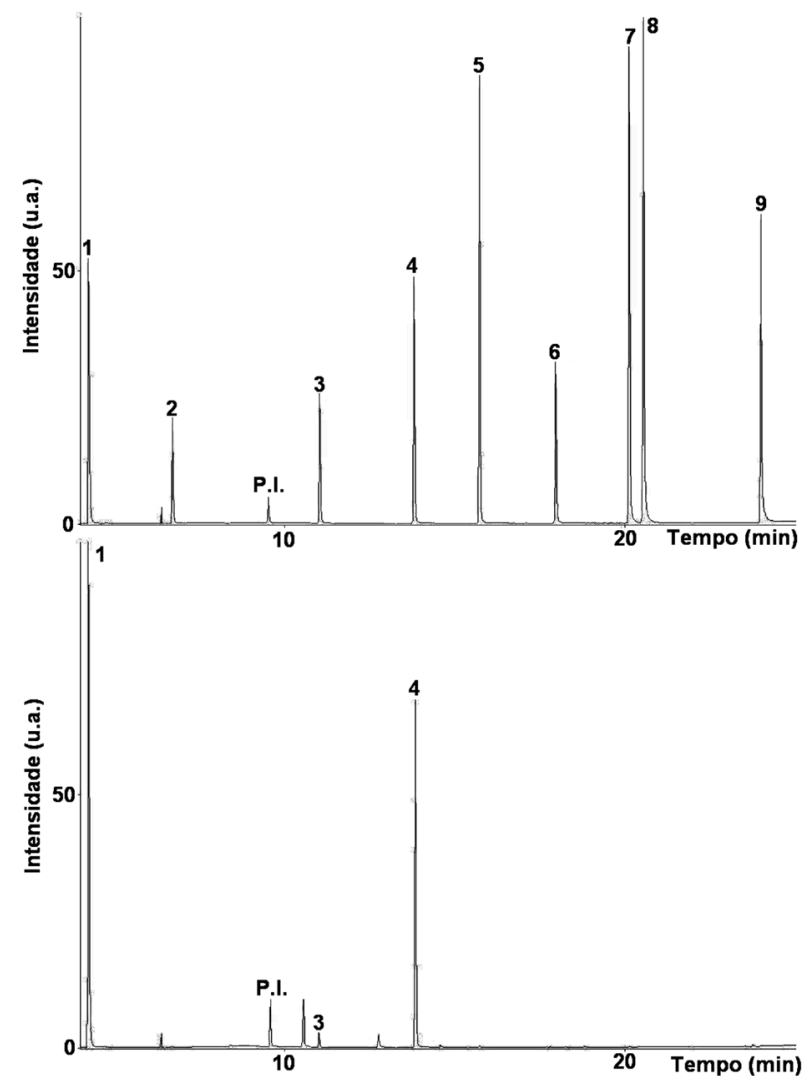

Figura 1. Cromatograma característico obtido por CG/EM-MSI; A-padrões analíticos; $B$ - amostra típica de cachaça; Picos: (1) acetato de etila (10,8 $\left.m g L^{-1}\right)$; (2) butanoato de etila (1,76 $\left.\mathrm{mg} \mathrm{L}^{-1}\right)$; (3) hexanoato de etila $(1,52 \mathrm{mg}$ $\left.L^{-1}\right)$; (4) lactato de etila (7,08 $\left.\mathrm{mg} \mathrm{L}^{-1}\right)$; (5) octanoato de etila (2,77 $\left.\mathrm{mg} \mathrm{L}^{-1}\right)$; (6) nonanoato de etila (1,01 $\left.\mathrm{mg} \mathrm{L}^{-1}\right)$; (7) decanoato de etila (2,75 $\left.\mathrm{mg} \mathrm{L}^{-1}\right)$; (8) octanoato de iso-amila (1,52 $\left.\mathrm{mg} \mathrm{L}^{-1}\right)$; (9) dodecanoato de etila (2,07 $\mathrm{mg}$ $\left.L^{-1}\right)$ e (P.I.) 4-metil-2-pentanol $\left(50,1 \mathrm{mg} \mathrm{L}^{-1}\right)$

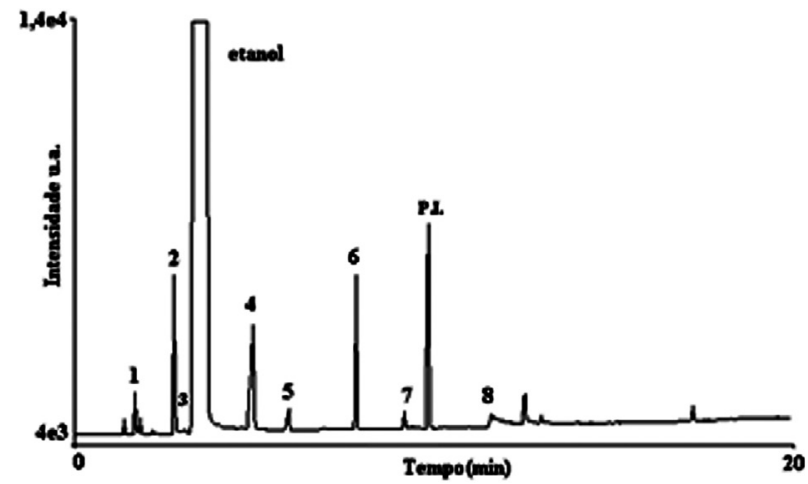

Figura 2. Cromatograma característico de uma amostra de cachaça obtido por CG/DIC; Picos: (1) acetaldeído; (2) acetato de etila; (3) metanol; (4) n-propanol; (5) iso-butanol; (6) n-butanol; (7) álcool iso-amílico; (8) ácido acético e (P.I.) n-hexanol

O lactato de etila pode ser facilmente quantificado utilizando CG/DIC, conforme ilustra a Figura 3, e sua inclusão na metodologia oficial (MAPA) não apresenta qualquer inconveniente técnico. Um experimento simples utilizando CG/DIC com as mesmas condições de análise propostas na metodologia por CG/EM ilustra a possibilidade do monitoramento do lactato de etila por esta técnica (Figura 3). Através da comparação dos cromatograma observa-se que os ésteres minoritários (butanoato de etila, hexanoato de etila, octanoato de etila, nonanoato de etila, decanoato de etila, octanoato de isoamila e dodecanoato de etila) são dificilmente detectados face à baixa sensibilidade do detector de ionização em chama. Problemas associados à coeluição também são evidentes, tornando necessário um aprimoramento das condições de separação cromatográfica e a inclusão de etapas de limpeza da amostra e pré-concentração para que os ésteres minoritários possam ser quantitativamente monitorados.
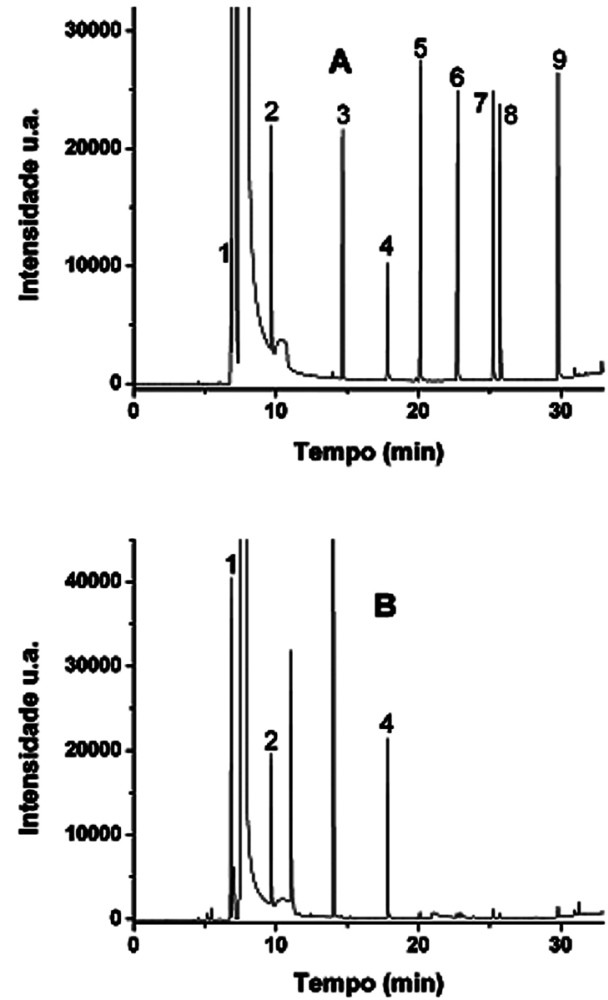

Figura 3. Cromatograma característico obtido por CG/DIC: A - padrões analíticos; B - amostra típica de cachaça. Picos: (1) acetato de etila; (2) butanoato de etila; (3) hexanoato de etila; (4) lactato de etila; (5) octanoato de etila; (6) nonanoato de etila; (7) decanoato de etila; (8) octanoato de iso-amila; (9) dodecanoato de etila

A presença do lactato de etila está associada à fermentação láctica que, apesar de ser uma fermentação concorrente da fermentação alcoólica, não afeta o rendimento de etanol. ${ }^{12}$ Embora a contribuição organoléptica desse éster ainda não esteja bem caracterizada, acreditase que seu aroma frutado venha a contribuir positivamente para o aroma da cachaça. Porém, em teores relativamente elevados, juntamente com seu baixo limiar de sensação $\left(14,0 \mathrm{mg} \mathrm{L}^{-1}\right),{ }^{16}$ o lactato de etila certamente pode mascarar outros aromas presentes na cachaça.

De acordo com a literatura, ${ }^{11}$ o lactato de etila é encontrado principalmente em amostras de cachaça e rum. Nas amostras de uísque este éster está presente em concentrações inferiores a $3 \mathrm{mg}$ $100 \mathrm{~mL}^{-1}$ álcool anidro. ${ }^{11} \mathrm{~A}$ baixa concentração de lactato de etila nas amostras de uísque é um indicativo da ausência de Lactobacillus spp durante o processo de fermentação ou um melhor controle do $\mathrm{pH}$ e da temperatura no processo fermentativo. A produção de uísque corriqueiramente emprega leveduras selecionadas e um estrito controle da contaminação microbiológica do pé de cuba e da temperatura. Tanto na produção de cachaça quanto na de rum, de modo geral, se utilizam leveduras selvagens, não selecionadas, e sem o desejado controle microbiológico do processo. Ainda, o caldo da cana-de-açúcar utilizado na produção da cachaça e do rum muitas vezes é fermentado 
em valores de $\mathrm{pH}$ mais elevados quando comparados aos do uísque. Acrescenta-se a isso o fato de a temperatura durante a fermentação não ser bem controlada, podendo alcançar até $45^{\circ} \mathrm{C}$.

A Tabela 4 apresenta a concentração total de ésteres para as amostras de cachaça comercial envelhecida utilizando a técnica de volumetria e CG/EM-MSI. A diferença encontrada na determinação de ésteres totais deve-se ao fato de que a volumetria é capaz de quantificar também os ésteres extraídos da madeira do tonel utilizado no envelhecimento da bebida. Em algumas amostras essa diferença é significativa, sendo que os ésteres totais determinados utilizando CG/ EM-MSI representam apenas 46,4\% dos ésteres totais determinados volumetricamente (Tabela 4). Os ésteres provenientes da madeira são geralmente de cadeia longa, alta massa molecular e característica da espécie de madeira utilizada (umburana, carvalho, amendoim). ${ }^{10}$ Estes ésteres não representam os ésteres originados durante o processo de fermentação, que são característicos da levedura utilizada (Saccharomyces spp).

Tabela 4. Concentração total de ésteres ( $\mathrm{mg} 100 \mathrm{~mL}^{-1}$ álcool anidro) para as amostras de cachaça comerciais envelhecidas (volumetria vs. CG/EM-MSI)

\begin{tabular}{lccc}
\hline Amostra & Volumetria* & CG/EM-MSI & $\begin{array}{c}\text { Acetato de etila } \\
(\text { CG/EM-MSI })\end{array}$ \\
\hline Cac01 & 58,7 & $35,9( \pm 0,31)$ & $20,4( \pm 0,29)$ \\
Cac02 & 32,4 & $24,8( \pm 0,79)$ & $13,3( \pm 0,78)$ \\
Cac03 & 69,7 & $37,8( \pm 0,41)$ & $23,4( \pm 0,40)$ \\
Cac04 & 63,0 & $47,1( \pm 0,21)$ & $38,2( \pm 0,18)$ \\
Cac05 & 100 & $107( \pm 1,02)$ & $85,6( \pm 1,01)$ \\
Cac06 & 45,8 & $24,4( \pm 0,25)$ & $17,1( \pm 0,22)$ \\
Cac07 & 47,9 & $47,5( \pm 0,50)$ & $37,2( \pm 0,48)$ \\
Cac08 & 171 & $79,3( \pm 1,15)$ & $65,9( \pm 1,15)$ \\
Cac09 & 55,7 & $44,9( \pm 0,58)$ & $33,0( \pm 0,52)$ \\
Cac10 & 46,3 & $32,0( \pm 0,42)$ & $21,3( \pm 0,36)$ \\
Cac11 & 73,4 & $68,2( \pm 0,81)$ & $11,6( \pm 0,07)$ \\
Cac12 & 38,6 & $22,4( \pm 0,12)$ & $12,6( \pm 0,04)$ \\
\hline
\end{tabular}

*Incerteza estimada em 2,2 mg $100 \mathrm{~mL}^{-1}$

\section{CONCLUSÃO}

A técnica volumétrica proposta pelo MAPA mostrou-se adequada para a determinação do teor total de ésteres presentes nas amostras de cachaça envelhecida. No entanto, cabem algumas considerações. Primeiramente, a determinação do teor total de ésteres em amostras de cachaça envelhecidas torna-se algumas vezes inviável, utilizando fenolftaleína como indicador, devido à coloração destas amostras, quer em consequência da adição de caramelo ou de sua estocagem em toneis de madeira. Nesse caso deve-se recorrer à utilização da potenciometria com eletrodo de vidro combinado para a determinação do ponto de equivalência. Como muitas vezes a concentração de etanol nas amostras de cachaça é variável, a determinação deste ponto pode não ser adequada, pois podem ocorrer variações no potencial de junção e nos coeficientes de atividade. Deve-se ressaltar, ainda, que a técnica volumétrica não é seletiva, não permitindo assim a especiação dos ésteres presentes nas amostras. Assim, como o mercado de consumo de bebidas destiladas, tanto interno quanto externo, torna-se cada vez mais exigentes, a determinação destes compostos que estão intimamente relacionados com o aroma da bebida é altamente desejável.

A cromatografia gasosa acoplada à espectrometria de massas é uma ferramenta praticamente indispensável dentro dos laboratórios de pesquisa nos dias de hoje e o custo deste equipamento vem diminuindo com o passar dos anos. A crescente demanda por produtos de qualidade pelo consumidor torna o uso do CG/EM cada vez mais necessário e no caso da cachaça sua presença é quase obrigatória, pois o controle de carbamato de etila nestas amostras é majoritariamente efetuado por este aparelho. ${ }^{17}$ Assim, a determinação do teor total de ésteres em amostras de cachaça utilizando CG/EM é factível em uma análise de rotina, permitindo uma desejável especiação dos analitos.

\section{AGRADECIMENTOS}

À FAPESP (Proc. No 04/15985-3) e ao CNPq (Proc. $N^{o}$ 471074/04-7) pelo suporte financeiro.

\section{REFERÊNCIAS}

1. Leão, D. A. F. S.; Dissertação de Mestrado, Universidade Federal de Pernambuco, Brasil, 2004.

2. Agencia Brazil, "Brazil tries to have cachaça recognized as an eminently Brazilian drink," June 10, 2003. http://www.radiobras.gov.br/materia. phtml?materia=154328\&editoria=, acessada em Março 2009.

3. Vancocelos, Y.; Pesquisa FAPESP 2003, 87, 74.

4. Boscolo, M.; Bezerra, C. W. B.; Cardoso, D. R.; Lima-Neto, B. S.; Franco, D. W.; J. Braz. Chem. Soc. 2000, 11, 86.

5. Nonato, E. A.; Carazza, F.; Silva, F. C. A.; Carvalho, C. R.; Cardeal, Z. L.; J. Agric. Food Chem. 2001, 49, 3533.

6. Nascimento, R. F.; Cardoso, D. R.; Keukeleire, D.; Lima-Neto, B. S.; Franco, D. W.; J. Agric. Food Chem. 2000, 48, 6070.

7. Cardoso, D. R.; Bettin, S. M.; Reche, R. V.; Lima-Neto, B. S.; Franco, D. W.; J. Food Compos. Anal. 2003, 16, 563

8. Suomalainen, H.; Lehtonen, M.; J. Inst. Brew. 1979, 85, 149.

9. Reazin, G. H.; Baldwin, S.; Scales, H. S.; Washington, H. W.; Andreasen, A. A.; J. Assoc. Off. Anal. Chem. 1976, 59, 770.

10. Vichi, S.; Santini, C.; Natali, N.; Riponi, C.; Lopez-Tamames, E.; Buxaderas, S.; Food Chem. 2007, 106, 1260.

11. Nascimento, E. S. P.; Cardoso, D. R.; Franco, D. W.; J. Agric. Food Chem. 2008, 56, 5488.

12. Geddes, P. A.; Riffkin, H. L. Em Distilled Beverage Flavour: Recent Developments; Piggott, J. R.; Paterson, A., eds.; VCH: New York, 1989, cap. 17.

13. BRASIL. Instrução Normativa ${ }^{\circ} 13$, de 29 de junho de 2005 , Ministério da Agricultura Pecuária e Abastecimento; Diário Oficial da União, seção 1 ; p. 3-4, 30/06/2005

14. http://www.agricultura.gov.br/portal/page?_pageid=33,1040761\&_ dad=portal\&_schema=PORTAL, acessada em Março 2009.

15. Miller, J. N.; Miller, J. C.; Statistics and Chemometrics for Analytical Chemistry, $4^{\text {th }}$ ed., Prentice Hall, 2000.

16. Fazzalari, F. A., ed.; Compilation of Odor and Taste Threshold Data, ASTM Data Series DS 48A, 1978.

17. Andrade-Sobrinho, L. G.; Boscolo, M.; Lima-Neto, B. S.; Franco, D. W.; Quim. Nova 2002, 25, 1074. 